\title{
Psycholinguistic Research of Creolized Advertising Texts: Age Factor
}

\author{
Svetlana V. Lebedeva ${ }^{1}$, and Antonina V. Annenkova ${ }^{2, *}$ \\ ${ }^{1}$ Kursk State University, Professional Communication and Foreign Languages Department, 305000, Kursk, Radisheva Street, 33, \\ Russia \\ ${ }^{2}$ Southwest State University, Foreign Languages Department, 305040, Kursk, 50 Let Oktyabrya Street, 94, Russia
}

\begin{abstract}
People daily deal with creolized texts that have become an integral part of life in modern society. One of such texts examples is advertising in educational sphere. The purpose of production and use of such texts is the formation of ideas, images and special relationship to the world or subject / object which is mediated by personal characteristics of an individual. Achieving this goal is possible by influencing the human consciousness and perception with the variety of psychological, psycholinguistic methods and other ways depending on the specific task. It should be noticed that subjective perception of a particular creolized text image is influenced not only by linguistic characteristics, but also by a large number of extralinguistic factors. The article shows some results of the experimental research which was conducted to prove "age" factor influence on the perception of creolized texts. In addition, some key issues related to practical application of a systematic approach for experimental data analysis as well as its application to linguistic science are discussed in the article.
\end{abstract}

\section{Introduction}

Nowadays many linguists recognize that for a more complete and detailed study of certain linguistic phenomena, it is necessary to go beyond the scope of linguistics and consider such individual's mental processes by which language material is acquired, organized and retrieved at the right time in the human brain. These mental processes have become the subject of psycholinguistics, the science created at the intersection of psychology and linguistics.

Charles Osgood defines psycholinguistics as a science that studies the processes where intentions (voice intentions) of speakers are transformed into signals of the code accepted in a certain culture, and these signals are converted into intentions of listeners. Thus, psycholinguistics deals with the encoding and decoding processes as they relate the message status to the status of participants of communication.

Among the main characteristic features of psycholinguistics there are the factor of the situation in which speech acts are produced and perceived, and the factor of a person producing or perceiving speech. One of the main problems of psycholinguistics is the peculiarities of production and perception of individual utterances and texts. When analyzing a text from the point of view of psycholinguistics, a researcher focuses on the linguistic identity and the processes of production and perception of a text are considered as a result of verbal and cognitive activities of an individual as a way of reflection of reality in the mind with the help of the elements of the language system [1]. A text in psycholinguistics is viewed dynamically as a product of speech activity. Therefore, any text should be studied within a particular communicative situation; form, content as well as perception of texts are determined by psychological characteristics of individuals - participants of communication.

It is beyond argument that advertising is considered to be one of the vital interdisciplinary issues, and many scientific papers [2-8] have been devoted to this key concept in consideration of this phenomena on all sides.

One of the modern trends in psycholinguistics is the study of creolized texts. The interest to the study of creolized advertising texts has been caused by their prevalence and typicality for the process of communication as well as by their social importance in modern society. Besides, experts in psycholinguistics are keenly interested in the role of non-verbal means in the semantic perception of the text. The presence of nonhomogeneous parts in the structure of creolized texts is considered by researchers as one of the ways to create a communicative stress in a text space as well as in the space of individuals perceiving this text. Creolized text has been studied by many scientists analyzing its different aspects and spheres of application and functioning [9-11]. In terms of linguistics, E.A. Lazareva [12] calls the process of crealization as a technique of an overlay of a text of one semantic field on a text with a different semantic field as the method of cognitive collision which is effectively used as a means of influencing and manipulating the consciousness of the recipient. The

* Corresponding author: Antonina-1984@yandex.ru 
starting point in psycholinguistic research of creolized texts according to E.E. Anisimova is the statement that the information perceived through various channels, including verbal and nonverbal ones, is integrated and processed in a single universal objective code of thinking [13]. At the same time, at the level of the deep semantics of the language there is no fundamental difference between the semantics of these characters. However, special studies show that the information transmitted verbally and nonverbally is perceived by different recipients in different ways.

Numerous psycholinguistic researchers confirm the complexity and diversity of the processes of perception and understanding of the text. The interpretation of one and the same text by different recipients may vary greatly $[14,15]$.

In the process of comprehension of any text, including creolized one, the individual necessarily uses his/her knowledge of the world. This knowledge helps him/her to better understand the text, to judge credibility or unreality of the events described. Therefore, we consider it necessary to separately identify physiological characteristics of an individual perceiving the text. Age characteristics define a person's image of the world which determines the differences in the perception and interpretation of the content components of the text.

The age of a person has an effect on his/her perception, since different age categories correspond to different life experiences, social conditions, and historical epochs. One and the same context in different age periods will be perceived differently by one and the same person. When creating creolized advertising texts, authors always take into consideration potential consumers' age because it greatly influences the success of their work: something interesting for elderly people will unlikely attract young men and teenagers.

Any world's phenomenon can be considered as a connection in the relations between its component elements forming a complex system which is a subject matter of system theory and has been under investigation for a long time by scientist from various intellectual fields [16-20]. It is known that language is a complex adaptive system: complex because it consists of many different interrelated elements; and adaptive because its elements can change over time adapting to changing conditions of environment, culture and society. The same kind of thing may be said about a creolized text as it is a combination of different language systems signs. In such a manner language and creolized advertising texts can be analyzed and described in terms of systemacity and system theory.

It is said that people at various live stages perceive the same information differently depending on their individuality, as well as a range of cultural, historical, ethnic, and socio-economic factors [21]. Any person's activity is based on ability to find out signs and situations that are the most important for him/her on the basis of similarity or differency. Interaction between an individual and the world around occurs by using language and numerous codes that can be represented by both verbally and visually.

According to the experiment goals, it is stated that representatives of different ages percept reality differently, and "age" factor directly affects the process. An integrative view of reality is formed on the basis of personal knowledge, experience, emotions, and feelings, and in spite of being objective there are differences in its subjective assessments.

\section{Main Part}

\subsection{Methodology}

To study "age" factor influence over vision formation of a creolized advertising text in a person's mind, a psycholinguistic experiment has been carried out.

For our goals we used a semantic differential method, which is considered as one of the methods to study the mass consciousness and to evaluate creolized advertising texts in particular. Being one of the project research methods, semantic differential allows one to take into account the fact that challenging situation makes sense not only because of its objective content, but also because of reasons related to the examinee's subjective inclination and impulses. In other words, it happens because of the subjective and personal values which are attached to the test situation by the examinee. As it can be said, the examinee projects his/her own properties onto the situation [22].

According to Charles Osgood, the semantic differential method can be used to measure connotative meanings which followed the perception of a stimulus object and were preceded by meaningful operations with a symbol. The closest analogue of connotative meaning in the conceptual apparatus of Soviet psychology is the notion of personal meaning which is the response value for the subject which can be seen in the works of A.A. Leontiev and A.N. Leontiev.

The differential method is a combination of controlled association and scaling procedures (Petrenko, 2005). The connection of the semantic differential method with the association method is shown in the works of K. Noble, A. Staats and K. Staats, which proved the presence of a high correlation between the Osgood's pragmatic value and Noble's measure of an associative connectivity of words. The measure of proximity of stimulus objects in the semantic differential method is similarity of assessments profiles and data obtained according to scales of the semantic differential.

Objects (concepts, images, characters etc.) measured in the experiment are assessed on a number of gradual bipolar scales (scales can be divided into three, five or seven points), which poles are usually given verbally. Concepts assessments by individual scales are correlated with each other. Scales with very high correlation with each other can be found using the factor analysis and then can be grouped into their factors. Charles Osgood considered the phenomenon of synesthesia as the psychological mechanism for interconnection and grouping scales into factors [23].

According to B.M. Velichkovsky, V.P. Zinchenko and A.R. Luria, synaesthesia is psychological phenomenon, which consists in origin of perception of one modality under the influence of stimulus of another modality [24]. 
A.R. Luria believed that the physiological mechanisms of synesthesia, which provide cross-modal transitions, are given by the fact that the stimulation of certain modality comes not only into the specific areas of the brain but also into both collaterals or side branches of axons and nonspecific projection zones of other modalities. A holistic intermodal image is reconstructed in perception on the basis of the perception of one modality. L. Marx, an American psychologist, considered synesthesia as a universal form of prelinguistic categorization, which provided a generalization at the level of the organism.

A transition from attributes given by scales to factors occurs by building a semantic space, which acts as metalanguage descriptions of values. This allows to conduct the semantic analysis by expanding the features in the selected alphabet of factors categories and then make judgments about their similarities and differences by calculating the distances between the respective values of the coordinate points into the semantic space [25].

The values in the semantic space possess two important features: the direction from the midpoint of each scale and the remoteness from the beginning of each scale, which indicates the intensity values [26].

The semantic space given by the standard semantic differential was originally defined by Charles Osgood and had three integrating factors: Evaluation factor, Potency factor, and Activity factor. It is commonly known as EPA space. According to the data obtained by Charles Osgood and his staff, which were repeatedly confirmed by other researchers, it can be said that above-mentioned integrating factors are universal or invariant to examinee's language and are corresponded to V. Wundt's three-component model of emotions (Pleasure, Elation, Ecstasy) [27].

P. Bentler and A. Lavoie expanded Charles Osgood's semantic space by adding Reality factor, Density factor, Rationality factor and Order factor. Russian scientists found a specific Comfortability factor on the base of Russian language. This factor is unique for Russian language and could not be found anywhere else [28]. We have chosen 15 bipolar scales/pairs on the basis of semantic differential according to V.F. Petrenko's factors. All the factors have been organized so that every factor includes three scales: Comfortability factor has scales 1 , 5, 6 (tender - rude; soft - hard; safe - dangerous), Order factor includes scales 2, 13, 14 (moving - motionless; regulated - chaotic; stable - changeable); Complexity factor has scales 3, 10, 11 (concrete - abstract; difficult easy; secret - usual), Evaluation factor has scales 4, 8, 9 (beautiful - ugly; useful - useless; pleasant - unpleasant); Activity factor consists of scales 7, 12, 15 (passive active; heavy - light; bright - dim).

Thus, depending on goals and objectives, which were set while planning a research, it is possible to vary the set of factors constituting the required semantic space.

An individual's system of settings in relation to concepts, which are important for him/her, can be found in his/her judgments, which are classified by consciousness under the scheme of logical dichotomies (antonymous adjectives). Bipolar evaluation, which arise in individual's mind, can be quantified by the semantic differential method [29].
For our research we decided to choose 10 creolized advertising texts of education advertising, which are information about the main specialties of one of Southwest State University (Kursk) [14,30]

The participants were to fill in a form of questionnaire. The respondents were to evaluate the objects in the table according to the given bipolar scales (from "-3" to " 3 ") relying on their first impression. Each line of the form should be filled with an answer. Time for the filling the form was unlimited. The participants were asked to specify their age.

The participants of the experiment are 42 people of different ages. All the respondents were divided into two groups by age:

- the first group of twenty two representatives between the age from 17 to 25 years old;

- the second group of twenty representatives between the age from 26 to 50 years old.

One of experiment tasks was to study presence or absence of systemacity between stimuli. Similar responses of advertising texts subjective perception as well as similar behavior of different age representatives can be studied to understand behavior of complex systems and reality phenomena peculiarities.

Modern science regards system concept as a common issue in applied sciences, it is not limited by theory. According to R. Ackoff rapid development of system concept is evident, and this issue has become a key one in scientific research. A trend to explore systems as a unit rather than assembly of parts corresponds to a modern science tendency not to isolate studied phenomena in a narrowly restricted context, but to study various interactions and explore more and more different aspects of nature [31,32].

As it was stated by E.T. Weckowicz language had been distinguished as symbolic system, and not simply a union of symbols, it was also considered as one of the most important man's achievements. Despite the fact that the symbols were originally created by a man, symbol systems could control human behavior and dominate him/her. According to L. von Bertalanffy open systems developmental law is applicable not only to biological systems development, but also to symbolic systems development. It should also be noted that culture and society are included into symbolic systems [33].

One of central concepts of system theory is feedback concept, which can be explained as an element connecting an output (response to a stimulus) with an input (stimulus) and used to control output change or vice versa. The simplest system with a feedback scheme proposed by L. von Bertalanffy is shown in Figure 1 [32]. In such scheme, respondent's feedback can not be fully predicted in advance.

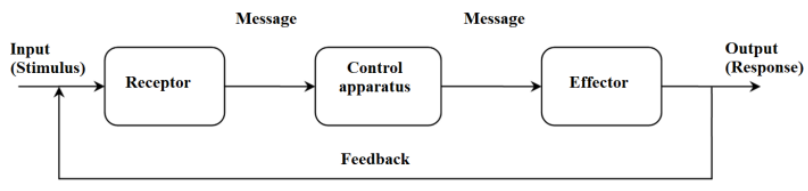

Fig. 1. Simple feedback scheme by L. von Bertalanffy. 
In the system (Figure 1) usual "stimulus-response" scheme is formed on the basis of external factors influence, which can be manipulated to bring to automation any required forms of social or antisocial behavior [34]. According to Z. Freud's theory the most important tendency of any organism's behavior is the tendency towards equilibrium. While assessing a stimulus object, respondents form their own subjective opinion, which reflects their internal state at experimentation time. One of researcher's goals in any psycholinguistic experiment is to evaluate and study responses, which are a set of data on subjects' emotional and psychological state, their socio-cultural environment, and other psycholinguistic parameters that directly influence research data. Person's psycho-physiological and mental activities are based on the ability to detect the most significant features and situations for life based on similarities and differences [36]

We have processed the obtained data by means of statistics methods and Microsoft Office Excel software.

\subsection{Data Analysis Procedures}

As it has been defined earlier a certain set of objects is always a system [35]. In order to determine and examine system components, it is necessary to find an element (a feature or an object) which combines scattered data into a general system. This element is known as a systemforming factor and is an indicator of systemacity.

To find out a system-forming factor, firstly, a correlation matrix for each class is to be built using the formula (1):

$$
r_{x y}=\frac{\sum\left(x-m_{x}\right) \times\left(y-m_{y}\right)}{\sqrt{\sum\left(x-m_{x}\right)^{2} \times \sum\left(y-m_{y}\right)^{2}}} .
$$

An estimation of correlation coefficient statistical significance was carried out by use of a two-sided Pearson criterion. Calculated correlation coefficients were compared to tabulated points obtained for two-sided Pearson criterion (confidential probability ' $\mathrm{p}$ ' is 0.95 / significance level is 0.05 ; degree of freedom ' $m$ ' is $n-2$, where ' $n$ ' is a number of subjects involved into an experiment), and not significant data were ommited [37].

Then, found correlation coefficients are ranked in a range of $[0 ; 10]$ by the formula (2):

$$
r_{x y}^{\prime}=\operatorname{round}\left(6 \pi\left(\cosh \left(r_{x y}\right)-1\right)\right) \text {. }
$$

To find out the presence or absence of connections between dynamic system elements, there is a need to analyze a correlation coefficient. If the value of a coefficient between two characteristics is less than a corresponding threshold value for the given degrees of freedom and significance level, then it can be said that the relationship between these characteristics is nonlinear. If a correlation coefficient is comparable and even greater than a corresponding threshold value, then it is said that there is a linear relationship between indicated characteristics. Results of an experimental research can be depicted by means of a state graph that corresponds to points or vertices (most often they are represented as circles) and a set of lines or edges which connect all points or part of these points (vertices). Graph sides determine the number of connections between the points or vertices. A graph is connected if each pair of its vertices is connected. It can be concluded that graph theory is an approprial tool for studying the objects structure and their relationships among each other [21].

Schematic diagrams of system-forming factors connectivity graphs for averaged data are shown in Figure 2 and Figure 3.

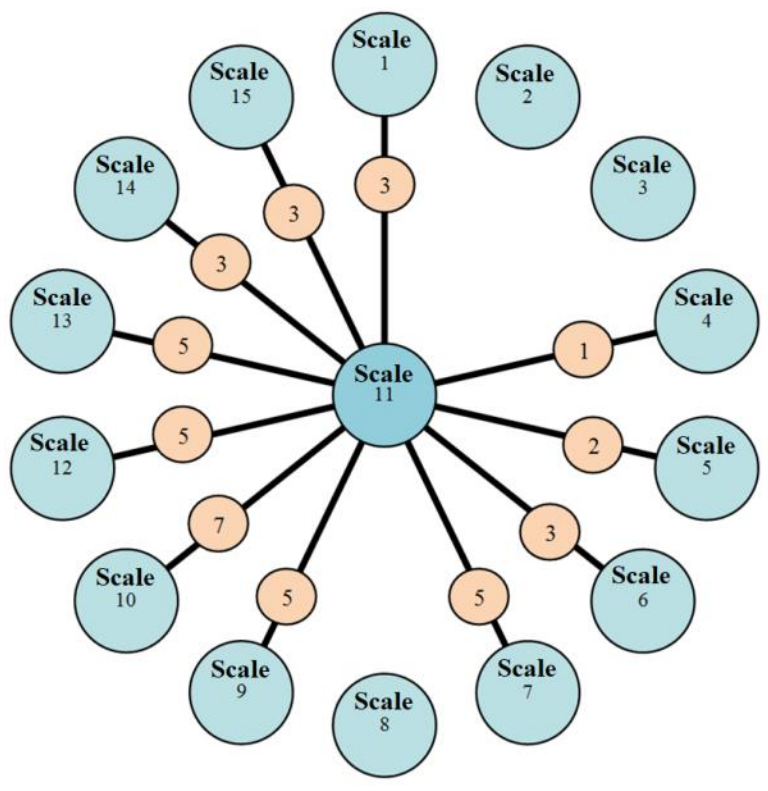

Fig. 2. An element of connectivity graph by "Scale 11" systemforming factor.

It can be said based on the Figure 2 data that the "Scale 11 " (secret - usual) is a system-forming factor. The strongest relationship is with "Scale 10" element; there is no relationship with "Scale 2", "Scale 3", and "Scale 8" elements, which means that they are independent from each other.

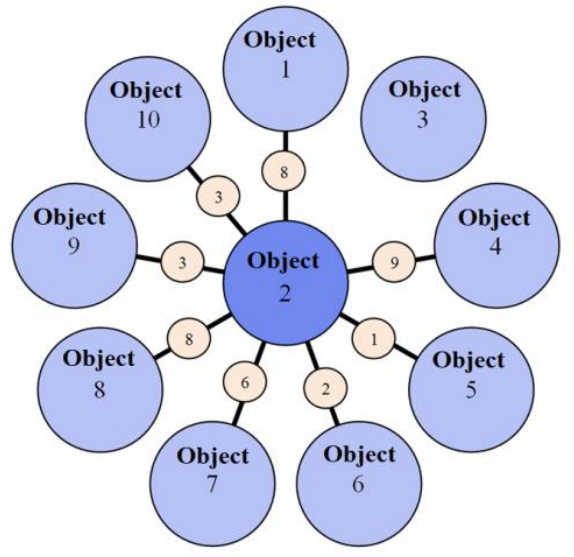

Fig. 3. An element of connectivity graph by "Object 2" systemforming factor.

It is evident from Figure 3 that "Object 2" is a systemforming factor among studied characteristics based on average data of both age groups. There is a strong 
relationship with "Object 1", "Object 4" and "Object 8" elements and no relationship with "Object 3".

Similar connectivity graphs for each studied age group have been drawn.

Based on experimental data, it is possible to make up a consolidated connectivity graph (Figure 4) to show similar and different objects for averaged data ("Object 2" is a system-forming factor), for the first age group ("Object 1" is a system-forming factor), and for the second age group ("Object 8 " is a system-forming factor).

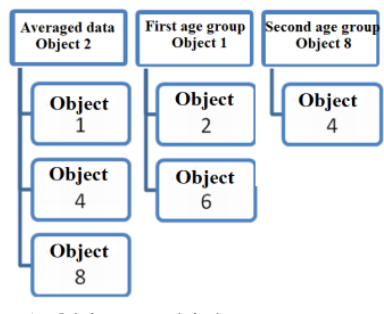

a) Objects which are strongly connected with each other

Fig. 4. Consolidated connectivity graph for similar and different characteristics expressed by "Object" factors.

It can be said based on the graph depicted in Figure 4a that there is a strong relationship between "Object 1 " and "Object 2" elements, "Object 4" and "Object 8" elements. "Object 3", "Object 5", and "Object 6" elements are the most different among each other (see Figure 4b).

Figure 5 presents a consolidated connectivity graph for "Scale" factor elements (see Figure 5).

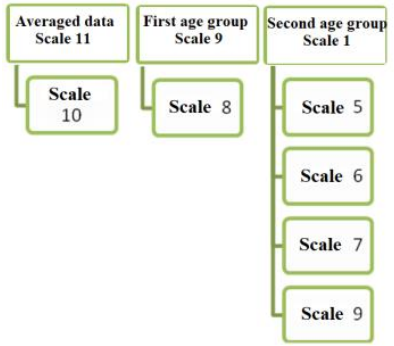

a) Objects which are strongly connected with each other

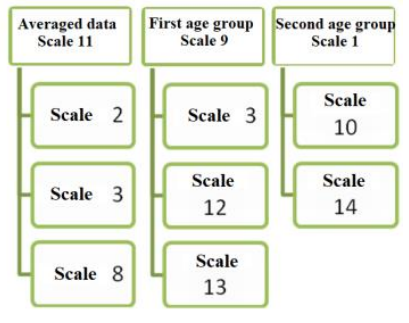

b) Objects which are divorced from each other
Fig. 5. Consolidated connectivity graph for similar and different characteristics expressed by "Scale" factors.

It can be concluded from Figure 5 graphs that it is impossible to distinguish similar and different elements in three studied cases (averaged data, the first age group and the second age group). In general this means that scales are independant and their simultaneous demonstration to a respondent do not influence on psycholinguistic experiment results.

After the fact of no strong relationship between the scales and objects has been proved, "age" factor influence on the creolized advertising texts perception has been analyzed.

It should be noted that we have defined object's load (social education advertising in this case) on each of the fifteen antonymous scales as an arithmetic mean value of the all respondents' responses of the corresponding age group [23].
It is convenient to analyze the experimental data if they are represented graphically. We have represented these data in the graphic form of two-dimensional space bar charts with the coordinate axis Object and Evaluation. The values of the representatives of different age groups' responses differ from one to another to a large extent. We have noted that most of the evaluations given by participants from the second age group tend to the extreme values. The absolute values (modulus) of the responses given by participants from the second age group exceed the corresponding figures given by the representatives from the first age group. Some participants gave the same assessment in a particular scale for each of the objects presented in the form of the questionnaire (most often it were the extreme values " -3 ', ' 3 ', and ' 0 '). This is explained by difficulty and impossibility respondents had faced while making a gradation according to the given scales. The main reason for this is differences in age, education, experience, ideology and worldview, social attitudes and stereotypes. To detailed study of each factor contribution into the assessment of the stimulus objects we have carried out the averaging of the all 15 scales.

The results of the research have been depicted in the graphic form of bar charts (Figure 6). The data are shown in averages of respondents' evaluations of advertising objects at 5 factors.

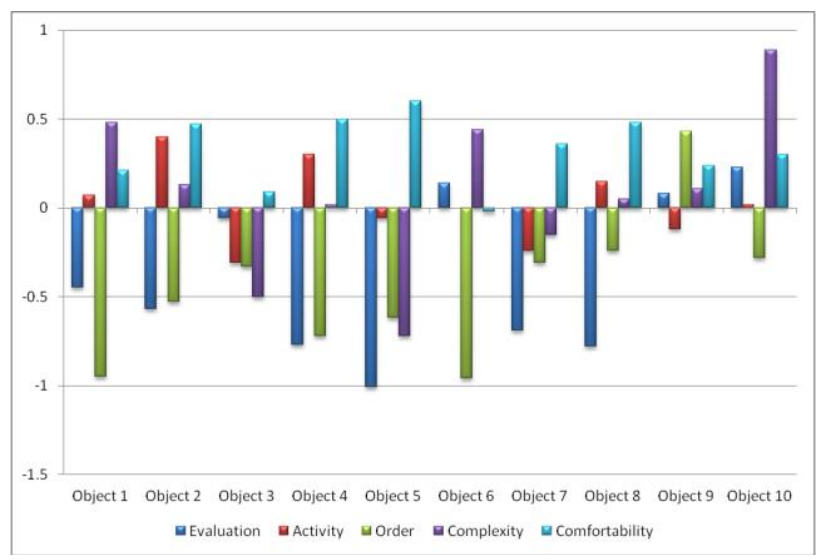

Fig. 6. Summarized data of the experiment.

We have analyzed the data obtained after averaging (see Figure 6) and made a conclusion that the dominant factors for almost all objects are Evaluation factor and Order factor, the exception is only "Object 10" with the dominant Complexity factor. The integrating Activity factor is the most insignificant. It reaches its maximum value (absolute value is close to " 0.5 ") in the average responses given to "Object 2", "Object 3" and "Object 4". All the averaged values of the objects on the factors range from "-2" to " 1 ". It can be assumed that the nature of nonverbal semantic differential given by the abstract objects, which contain both visual and verbal components, causes a shift evaluation descriptions to reflection of characteristics which are more affordable to imaging.

\section{CONCLUSION}


Everyone's vision of the world depends on many factors; among them there is age. The emotional perception of education creolized advertising texts based on individual experience are influenced by inner feelings of an individual so that they become an integral characteristic feature of the image concealed in a advertising text and that can be traced back when conducting a psycholinguistic experiment.

A semantic differential method makes it possible to investigate not only the meaning but emotional coloring of words as well to obtain the structure individual's or group's responses. Concepts evaluations by these factors allow one to build a fragment of individual's semantic space or conceptual structure as it was stated by N.V. Rodionova [38]. Thus, the results of the research show that the process of perception of the education advertising is affects by many factors and is reflected in the subjective assessments given by individuals during the research.

To sum it up, it has been found out that the age, social life and personal experience of the participants influence their responses. We have indicated differences in comments of two age groups: respondents of the age group from 26 to 50 years old assess the objects better trying to analyze and take into consideration all sides of them.

The received data can be used for further study of the basic laws of age factor influence on the certain individual's subjective reactions formation in response to the given stimuli. Identification of the semantic space construction of the studied advertising texts received by using subjective assessments of different age groups can be also examined at a latter stage.

\section{References}

1. V.P. Belyanin, Basics of Psycholinguistic Diagnosis: the World Model in Literature (Moscow: Trivola, 2000)

2. J. Huang, S. Su, L. Zhou, Xi Liu, Journal of Interactive Marketing 27(1) (February), 36-46 (2013)

3. I. Petrovicia, Procedia - Social and Behavioral Sciences 149, 719-723 (2014)

4. M. Dehghani, M.K. Niaki, I. Ramezani, R. Sali, Computers in Human Behavior 59 (June), 165-172 (2016)

5. K. Kim, S. Lee, Y.K. Choi, Journal of Business Research 4 (September) (2017)

6. A. Grunewald, M. Kräkel, International Journal of Industrial Organization 55 (November), 91-113 (2017)

7. R. Bell, A. Buchner, Journal of Interactive Marketing 41, 1-13 (2018)

8. B. Dindaroglu, Information Economics and Policy 42, 66-75 (2018)

9. C.-G. Voicu, Caribbean Cultural Creolization, Procedia - Social and Behavioral Sciences 149, 9971002 (2014)
10. I. Platonova, E. Tarasova, A. Golubinskaya, Procedia - Social and Behavioral Sciences 214, 788-796 (2015)

11. C. Jourdan, International Encyclopedia of the Social \& Behavioral Sciences (Second Edition), 117-121 (2015)

12. E.A. Lazareva, E.V. Gorina, Linguistics (Ekaterinburg) 11, 103-112 (2003)

13. E.E. Anisimova, Text Linguistics and Intercultural Communication (on the Basis of Creolized Texts): Tutorials for Students of Foreign Languages Departments (Moscow: Academia, 2003)

14. O.S. Zubkova, A.V. Annenkova, Peculiarities of Image Advertising Visions Functioning in Individual Lexicon: monograph, (Kursk, Southwest State University, published by Academic Book, CJSC, 2017)

15. O.S. Zubkova, A.V. Annenkova, MJLTM 7(8) (August). 189-202 (2017b)

16. K. Millová, M. Blatný, International Encyclopedia of the Social \& Behavioral Sciences (Second Edition), 879-883 (2015)

17. M.E. Schneider, International Encyclopedia of the Social \& Behavioral Sciences (Second Edition), 946950 (2015)

18. R. Petersen, Annual Reviews in Control 42, 309-318 (2016)

19. D.S. Demetis, A.S. Lee, Information and Organization 26(4) (December), 116-126 (2016)

20. P.B. Badcock, C.G. Davey, S. Whittle, N.B. Allen, K.J. Friston, Trends in Cognitive Science 21(3) (March), 182-194 (2017)

21. G.F. Luger, Artificial Intellect: Structures and Strategies for Complex Problem Solving, 4th ed., published by Wiliame publishing company (2003)

22. V.A. Yadov, Social Research: Methodology, Program and Methods (Moscow: Nauka, 1987)

23. V.F. Petrenko, Basics of Psychosemantics. Second edition. Enlarged edition (Saint Petersburg: Peter, 2005)

24. B.M. Velichkovsky, V.P. Zinchenko, A.R. Luria, The psychology of Perception (Moscow: Publisher of Moscow University, 1973)

25. I.T. Kasavin, Encyclopedia of Epistemology and Philosophy of Science. Under the General Editorial of Kasavin, I.T., (Moscow: Canon Plus, Regional Social Organization of the Disabled People 'Reabilitaciya', 2009)

26. R. Corsini, Psychological Encyclopedia. Second Edition. Under the General Editorial of Corsini R., Auerbach A. (Saint Petersburg: Peter, 2006)

27. V.P. Serkin, Psychosemantics Methods (Moscow: Aspekt Press, 2004)

28. V.F. Petrenko, Introduction to Experimental Psychosemantics: Study of the Forms of Representation in Everyday Consciousness (Moscow: Publisher of Moscow University, 1983) 
29. I.V. Zakharov, G.A. Stryukova, Psychological Science and Education 3-4, 30-35 (1997)

30. A.V. Annenkova, Scientific Notes 2(30) (2014)

31. R.L. Ackoff, Games, General Systems IV, 145-150 (1959)

32. L. von. Bertalanffy, General Systems VII, 1-20 (1962)

33. E.T. Weckowicz, Center for Systems Research, Working Paper 89-2 (Edmonton AB: University of Alberta) (1989).

34. T.I. Zakharova, Organisational Behaviour: academic and methodological complex (Moscow: Publishing Center of Eurasian Open, 2009)

35. A.V. Annenkova, Systems Theory as an Interpretation Method of Psycholinguistic Research Results, Paper presented at Language for Specific Purpoces: System, Functions, Environment. The Fifth International Conference at Southwest State University (Kursk: Publisher of Southwest State University, 2014)

36. S.V. Lebedeva, Language Theory and Intercultural Communication 1(15), 45-48 (2014)

37. R.A. Fisher, Y. Frank, Statistical Tables for Biological, Agricultural and Medical Research, 6th ed., (Longman Group, Ltd., England., 1953)

38. N.V. Rodionova, Sociology (Moscow) 7, 161-183 (1997) 